\title{
Common fixed point theorems for generalized cyclic contraction pairs in $b$-metric spaces with applications
}

\author{
Oratai Yamaod ${ }^{1}$, Wutiphol Sintunavarat ${ }^{1 *}$ and Yeol Je Cho $2,3^{*}$
}

\section{"Correspondence:}

wutiphol@mathstat.sci.tu.ac.th; yjcho@gnu.ac.kr

'Department of Mathematics and

Statistics, Faculty of Science and Technology, Thammasat University

Rangsit Center, Pathumthani, 12121, Thailand

${ }^{2}$ Department of Mathematics Education and the RINS,

Gyeongsang National University, Jinju, 660-701, Korea

Full list of author information is

available at the end of the article

\section{Springer}

\begin{abstract}
In this paper, we introduce the notion of generalized cyclic contraction pairs in $b$-metric spaces and establish some fixed point theorems for such pairs. Also, we give some examples to illustrate the main results which properly generalizes some results given by some authors in literature. Further, by using the main results, we prove some common fixed point results for generalized contraction pairs in partially ordered $b$-metric spaces. Our results generalize and improve the result of Shatanawi and Postolache (Fixed Point Theory Appl. 2013:60, 2013) and several well-known results given by some authors in metric and $b$-metric spaces.
\end{abstract}

MSC: $47 \mathrm{H} 09 ; 47 \mathrm{H} 10$

Keywords: $b$-metric spaces; common fixed points; cyclic contraction mappings; partially ordered set

\section{Introduction}

Fixed point theory plays a basic role in applications of many branches of mathematics. Finding fixed points of generalized contraction mappings has become the focus of strong research activity in fixed point theory. Recently, many authors have published many papers on fixed point theory and applications in several ways. One of the recently popular topics in fixed point theory is to show the existence of fixed points of cyclic contraction mappings in several spaces. In 2003, Kirk et al. [1] introduced concepts of cyclic mappings and cyclic contraction mappings and also gave some interesting fixed point theorems for these mappings. Later, several mathematicians have been studying fixed point results for cyclic mappings satisfying generalized contraction conditions (see in [2-5]).

In 2013, Shatanawi and Postolache [6] introduced the notion of a generalized cyclic contraction for the pair of self-mappings in partially ordered metric spaces and proved some common fixed point theorems for such a pair by using the idea of altering distance functions due to Khan et al. [7].

On the other hand, in 1989, Bakhtin [8] introduced the concept of $b$-metric spaces as a generalization of metric spaces and also proved Banach's contraction principle in $b$-metric spaces, which is a generalization of Banach's contraction principle in metric spaces. Afterward, many mathematicians have studied fixed point results for single-valued and multivalued mappings in $b$-metric spaces (see [9-13]).

(C) 2015 Yamaod et al. This article is distributed under the terms of the Creative Commons Attribution 4.0 International License (http://creativecommons.org/licenses/by/4.0/), which permits unrestricted use, distribution, and reproduction in any medium, provided you give appropriate credit to the original author(s) and the source, provide a link to the Creative Commons license, and indicate if changes were made. 
In this paper, we introduce the concept of new generalized cyclic contraction pairs in $b$-metric spaces and establish some fixed point theorems for such pairs in the setting of $b$-metric spaces. Also, we give some examples to illustrate that our results properly generalize some results given by some authors in literature. Further, by using our main results, we give some common fixed results in partially ordered $b$-metric spaces. Our result generalizes and improves the corresponding results of Shatanawi and Postolache [6] and several well-known results of fixed point and common fixed point theorems given by some authors in metric and $b$-metric spaces.

\section{Preliminaries}

Throughout this paper, we denote by $\mathbb{N}, \mathbb{R}_{+}$and $\mathbb{R}$ the sets of positive integers, nonnegative real numbers and real numbers, respectively.

In 1984, Khan et al. [7] introduced the concept of an altering distance function as follows.

Definition 2.1 The function $\varphi:[0, \infty) \rightarrow[0, \infty)$ is called an altering distance function if the following properties hold:

(1) $\varphi$ is continuous and nondecreasing;

(2) $\varphi(t)=0$ if and only if $t=0$.

The following examples illustrate the definition.

Example 2.2 Let $\varphi_{1}, \varphi_{2}:[0, \infty) \rightarrow[0, \infty)$ be defined by

$$
\varphi_{1}(t)=(1-k) t \quad \text { and } \quad \varphi_{2}(t)=t^{l}
$$

for all $t \in[0, \infty)$, where $k \in[0,1)$ and $l \in(0, \infty)$. Then the functions $\varphi_{1}$ and $\varphi_{2}$ are altering distance functions (see the geometry of the functions $\varphi_{1}$ and $\varphi_{2}$ in Figure 1).

In 2003, Kirk et al. [1] introduced the concepts of cyclic mappings and cyclic contractions as follows.

Definition 2.3 ([1]) Let $A$ and $B$ be nonempty subsets of a metric space $(X, d)$. A mapping $f: A \cup B \rightarrow A \cup B$ is said to be cyclic if $f(A) \subseteq B$ and $f(B) \subseteq A$.
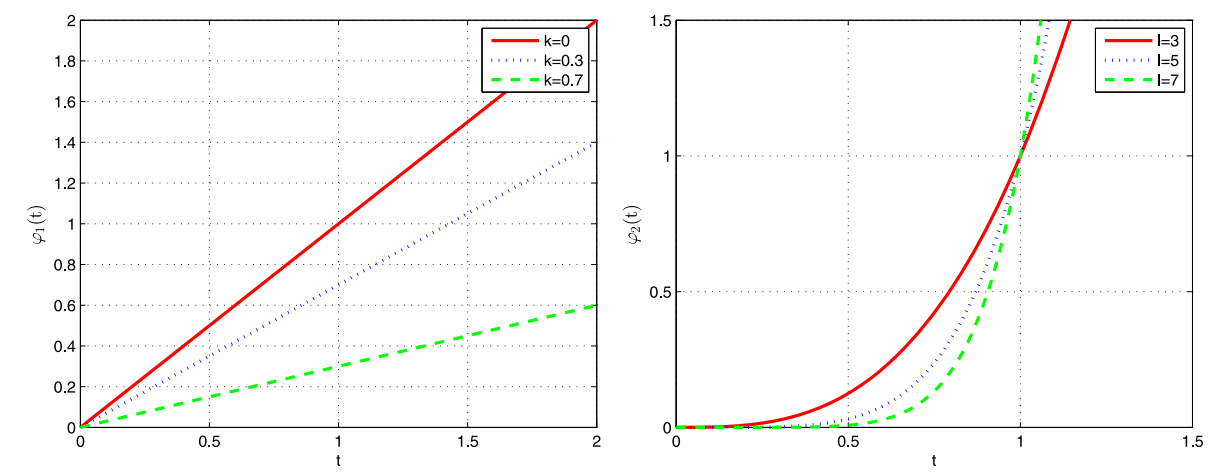

Figure 1 Geometry of functions $\varphi_{1}$ and $\varphi_{2}$. 
Definition 2.4 ([1]) Let $A$ and $B$ be nonempty subsets of a metric space $(X, d)$. A mapping $f: A \cup B \rightarrow A \cup B$ is called a cyclic contraction if there exists $k \in[0,1)$ such that

$$
d(f x, f y) \leq k d(x, y)
$$

for all $x \in A$ and $y \in B$.

On the other hand, Bakhtin [8] introduced the concept of a $b$-metric space as follows.

Definition 2.5 ([8]) Let $X$ be a nonempty set and $s \geq 1$. Suppose that the mapping $d$ : $X \times X \rightarrow \mathbb{R}_{+}$satisfies the following conditions:

(1) $0 \leq d(x, y)$ for all $x, y \in X$ and $d(x, y)=0$ if and only if $x=y$;

(2) $d(x, y)=d(y, x)$ for all $x, y \in X$;

(3) $d(x, y) \leq s[d(x, z)+d(z, y)]$ for all $x, y, z, \in X$.

Then $(X, d)$ is called a $b$-metric space with coefficient $s$.

Every metric space is a $b$-metric space with $s=1$ and so the class of $b$-metric spaces is larger than the class of metric spaces. In general, a $b$-metric space does not necessarily need to be a metric space.

Now, we give some known examples of a $b$-metric which show that a $b$-metric space is a real generalization of metric spaces as follows.

Example 2.6 Let $X=\mathbb{R}$ and a mapping $d: X \times X \rightarrow \mathbb{R}_{+}$be defined by

$$
d(x, y)=|x-y|^{2}
$$

for all $x, y \in X$. Then $(X, d)$ is a $b$-metric space with coefficient $s=2$.

Example 2.7 The set $l_{p}(\mathbb{R})$ with $0<p<1$, where

$$
l_{p}(\mathbb{R}):=\left\{\left\{x_{n}\right\} \subseteq \mathbb{R}: \sum_{n=1}^{\infty}\left|x_{n}\right|^{p}<\infty\right\},
$$

together with the mapping $d: l_{p}(\mathbb{R}) \times l_{p}(\mathbb{R}) \rightarrow \mathbb{R}_{+}$defined by

$$
d(x, y):=\left(\sum_{n=1}^{\infty}\left|x_{n}-y_{n}\right|^{p}\right)^{\frac{1}{p}}
$$

for each $x=\left\{x_{n}\right\}, y=\left\{y_{n}\right\} \in l_{p}(\mathbb{R})$ is a $b$-metric space with coefficient $s=2^{\frac{1}{p}}>1$. The above result also holds for the general case $l_{p}(X)$ with $0<p<1$, where $X$ is a Banach space.

Example 2.8 Let $p$ be a given real number in the interval $(0,1)$. The space $L_{p}[0,1]$ of all real functions $x(t), t \in[0,1]$ such that $\int_{0}^{1}|x(t)|^{p} d t<1$ together with the mapping $d: L_{p}[0,1] \times$ $L_{p}[0,1] \rightarrow \mathbb{R}_{+}$defined by

$$
d(x, y):=\left(\int_{0}^{1}|x(t)-y(t)|^{p} d t\right)^{1 / p}
$$

for each $x, y \in L_{p}[0,1]$ is a $b$-metric space with constant $s=2^{\frac{1}{p}}$. 
Next, we give the concepts of convergence, a Cauchy sequence, $b$-continuity, and completeness and closedness in a $b$-metric space.

Definition 2.9 ([10]) Let $(X, d)$ be a $b$-metric space. Then a sequence $\left\{x_{n}\right\}$ in $X$ is called:

(1) $b$-convergent if there exists $x \in X$ such that $d\left(x_{n}, x\right) \rightarrow 0$ as $n \rightarrow \infty$; in this case, we write $\lim _{n \rightarrow \infty} x_{n}=x$;

(2) a b-Cauchy sequence if $d\left(x_{n}, x_{m}\right) \rightarrow 0$ as $n, m \rightarrow \infty$.

Proposition 2.10 ([10]) In a $b$-metric space $(X, d)$, the following assertions hold:

(1) a b-convergent sequence has a unique limit;

(2) each b-convergent sequence is a b-Cauchy sequence;

(3) in general, a b-metric is not continuous.

We need the following lemma as regards $b$-convergent sequences in the proof of our results.

Lemma $2.11([14])$ Let $(X, d)$ be a b-metric space with coefficient $s \geq 1$ and let $\left\{x_{n}\right\},\left\{y_{n}\right\}$ be $b$-convergent to the points $x, y \in X$, respectively. Then we have

$$
\frac{1}{s^{2}} d(x, y) \leq \liminf _{n \rightarrow \infty} d\left(x_{n}, y_{n}\right) \leq \limsup _{n \rightarrow \infty} d\left(x_{n}, y_{n}\right) \leq s^{2} d(x, y)
$$

In particular, if $x=y$, then we have $\lim _{n \rightarrow \infty} d\left(x_{n}, y_{n}\right)=0$. Moreover, for each $z \in X$,

$$
\frac{1}{s} d(x, z) \leq \liminf _{n \rightarrow \infty} d\left(x_{n}, z\right) \leq \limsup _{n \rightarrow \infty} d\left(x_{n}, z\right) \leq s d(x, z) .
$$

Definition $2.12([10])$ Let $(X, d)$ and $\left(X^{\prime}, d^{\prime}\right)$ be two $b$-metric spaces.

(1) The space $(X, d)$ is $b$-complete if every $b$-Cauchy sequence in $X b$-converges;

(2) a function $f: X \rightarrow X^{\prime}$ is $b$-continuous at a point $x \in X$ if it is $b$-sequentially continuous at $x$, that is, whenever $\left\{x_{n}\right\}$ is $b$-convergent to $x,\left\{f x_{n}\right\}$ is $b$-convergent to $f x$.

Definition 2.13 ([10]) Let $Y$ be a nonempty subset of a $b$-metric space $(X, d)$. The closure $\bar{Y}$ of $Y$ is the set of limits of all $b$-convergent sequences of points in $Y$, i.e.,

$$
\bar{Y}=\left\{x \in X: \text { there exists a sequence }\left\{x_{n}\right\} \text { in } Y \text { so that } \lim _{n \rightarrow \infty} x_{n}=x\right\} .
$$

Definition 2.14 ([10]) Let $(X, d)$ be a $b$-metric space. Then a subset $Y \subseteq X$ is said to be closed if and only if, for each sequence $\left\{x_{n}\right\}$ in $Y$ which $b$-converges to a point $x$, we have $x \in Y($ i.e., $\bar{Y}=Y)$.

In 2014, Sintunavarat [15] (see also [16]) introduced the useful concept of transitivity for mappings as follows.

Definition $2.15([15,16])$ Let $X$ be a nonempty set. The mapping $\alpha: X \times X \rightarrow[0, \infty)$ is said to be transitive if, for all $x, y, z \in X$,

$$
\alpha(x, y) \geq 1, \quad \alpha(y, z) \geq 1 \quad \Longrightarrow \quad \alpha(x, z) \geq 1 .
$$




\section{Main results}

Let $(X, d)$ be a $b$-metric space with coefficient $s \geq 1$ and $f, g: X \rightarrow X$ be two self-mappings. Throughout this paper, unless otherwise stated, for all $x, y \in X$, let

$$
M_{s}(x, y):=\max \left\{d(x, y), d(x, f x), d(y, g y), \frac{d(x, g y)+d(y, f x)}{2 s}\right\} .
$$

If $s=1$, we write $M(x, y)$ instead $M_{s}(x, y)$, that is,

$$
M(x, y):=\max \left\{d(x, y), d(x, f x), d(y, g y), \frac{d(x, g y)+d(y, f x)}{2}\right\} .
$$

Definition 3.1 Let $A, B$ be two nonempty closed subsets of a $b$-metric space $(X, d)$ with coefficient $s \geq 1, \alpha: X \times X \rightarrow[0, \infty), \psi:[0, \infty) \rightarrow[0, \infty)$ and $f, g: X \rightarrow X$ be four mappings. The pair $(f, g)$ is called an cyclic $\alpha-(\psi, A, B)_{s}$-contraction if

(1) $\psi$ is an altering distance function;

(2) $A \cup B$ has a cyclic representation w.r.t. the pair $(f, g)$, that is, $f(A) \subseteq B, g(B) \subseteq A$, and $X=A \cup B$

(3) there exists $0<\delta<1$ such that the following condition holds:

$$
\begin{gathered}
x \in A, y \in B \quad \text { with } \alpha(x, y) \geq 1 \text { or } \alpha(y, x) \geq 1 \\
\Longrightarrow \quad \psi\left(s^{3} d(f x, g y)\right) \leq \delta \psi\left(M_{s}(x, y)\right) .
\end{gathered}
$$

Definition 3.2 Let $A, B$ be two nonempty closed subsets of a $b$-metric space $(X, d)$ with $X=A \cup B$ and $\alpha: X \times X \rightarrow[0, \infty)$ and $f, g: X \rightarrow X$ be three mappings. The pair $(f, g)$ is said to be $\alpha-(A, B)$-weakly increasing if $\alpha(f x, g f x) \geq 1$ for all $x \in A$ and $\alpha(g x, f g x) \geq 1$ for all $x \in B$.

Now, we give the main results in this section.

Theorem 3.3 Let $(X, d)$ be a complete b-metric space with coefficient $s \geq 1$ and $A, B$ be nonempty closed subsets of $X$. Suppose that $\alpha: X \times X \rightarrow[0, \infty), \psi:[0, \infty) \rightarrow[0, \infty)$ and $f, g: X \rightarrow X$ are four mappings such that the pair $(f, g)$ is $\alpha-(A, B)$-weakly increasing and the following conditions hold:

(1) the pair $(f, g)$ is a cyclic $\alpha-(\psi, A, B)_{s}$-contraction;

(2) $f$ or $g$ is b-continuous;

(3) $\alpha$ is a transitive mapping;

(4) if $\left\{x_{n}\right\}$ is sequence in $X$ such that $\alpha\left(x_{n}, x_{n+1}\right) \geq 1$ and $x_{n} \rightarrow z$ as $n \rightarrow \infty$, then $\alpha(z, z) \geq 1$.

Then $f$ and $g$ have a common fixed point in $A \cap B$.

Proof Choose $x_{0} \in A$. Let $x_{1}:=f x_{0}$. Since $f(A) \subseteq B$, we have $x_{1} \in B$. Also, let $x_{2}:=g x_{1}$. Since $g(B) \subseteq A$, we have $x_{2} \in A$. Continuing this process, we can construct a sequence $\left\{x_{n}\right\}$ in $X$ such that

$$
x_{2 n+1}=f x_{2 n} \in B, \quad x_{2 n+2}=g x_{2 n+1} \in A
$$

for all $n \in \mathbb{N} \cup\{0\}$. Since $f$ and $g$ are $\alpha-(A, B)$-weakly increasing, we have $\alpha\left(f x_{0}, g f x_{0}\right) \geq 1$ and $\alpha\left(g x_{1}, f g x_{1}\right) \geq 1$. This implies that $\alpha\left(x_{1}, x_{2}\right) \geq 1$ and $\alpha\left(x_{2}, x_{3}\right) \geq 1$. Repeating this process, we 
obtain

$$
\alpha\left(x_{n}, x_{n+1}\right) \geq 1
$$

for all $n \in \mathbb{N} \cup\{0\}$. From (3.1), we have

$$
\begin{aligned}
\psi\left(s^{3} d\left(x_{n+1}, x_{n+2}\right)\right) & =\psi\left(s^{3} d\left(f x_{n}, g x_{n+1}\right)\right) \\
& \leq \delta \psi\left(M_{s}\left(x_{n}, x_{n+1}\right)\right)
\end{aligned}
$$

for all $n \in \mathbb{N} \cup\{0\}$.

Now, we complete the proof by the following three steps:

Step I. We prove that $\lim _{k \rightarrow \infty} d\left(x_{k}, x_{k+1}\right)=0$. For each $k \in \mathbb{N} \cup\{0\}$, we define $d_{k}:=$ $d\left(x_{k}, x_{k+1}\right)$. Now, we assume that $d_{k_{0}}=0$ for some $k_{0} \in \mathbb{N} \cup\{0\}$. This implies that $x_{k_{0}}=x_{k_{0}+1}$. If $k_{0}=2 n$ for some $n \in \mathbb{N}$, then $x_{2 n}=x_{2 n+1}$.

Next, we show that $x_{2 n+1}=x_{2 n+2}$. Since $\alpha\left(x_{2 n}, x_{2 n+1}\right) \geq 1$, we have

$$
\begin{aligned}
\psi\left(s^{3} d\left(x_{2 n+1}, x_{2 n+2}\right)\right) & =\psi\left(s^{3} d\left(f x_{2 n}, g x_{2 n+1}\right)\right) \\
& \leq \delta \psi\left(M_{s}\left(x_{2 n}, x_{2 n+1}\right)\right),
\end{aligned}
$$

where

$$
\begin{aligned}
& M_{s}\left(x_{2 n}, x_{2 n+1}\right) \\
& =\max \left\{d\left(x_{2 n}, x_{2 n+1}\right), d\left(x_{2 n}, f x_{2 n}\right), d\left(x_{2 n+1}, g x_{2 n+1}\right), \frac{d\left(x_{2 n}, g x_{2 n+1}\right)+d\left(x_{2 n+1}, f x_{2 n}\right)}{2 s}\right\} \\
& =\max \left\{d\left(x_{2 n}, x_{2 n+1}\right), d\left(x_{2 n}, x_{2 n+1}\right), d\left(x_{2 n+1}, x_{2 n+2}\right), \frac{d\left(x_{2 n}, x_{2 n+2}\right)+d\left(x_{2 n+1}, x_{2 n+1}\right)}{2 s}\right\} \\
& =d\left(x_{2 n+1}, x_{2 n+2}\right) .
\end{aligned}
$$

Therefore, from (3.3), it follows that

$$
\psi\left(s^{3} d\left(x_{2 n+1}, x_{2 n+2}\right)\right) \leq \delta \psi\left(d\left(x_{2 n+1}, x_{2 n+2}\right)\right) \leq \delta \psi\left(s^{3} d\left(x_{2 n+1}, x_{2 n+2}\right)\right) .
$$

Since $\delta<1$, we have $\psi\left(s^{3} d\left(x_{2 n+1}, x_{2 n+2}\right)\right)=0$ and hence $x_{2 n+1}=x_{2 n+2}$.

Similarly, if $k_{0}=2 n+1$ for some $n \in \mathbb{N} \cup\{0\}$, then $x_{2 n+1}=x_{2 n+2}$ gives $x_{2 n+2}=x_{2 n+3}$. Consequently, the sequence $\left\{d_{k}\right\}$ becomes constant for $k \geq k_{0}$ and hence $\lim _{k \rightarrow \infty} d\left(x_{k}, x_{k+1}\right)=0$. This completes this step. Therefore, we suppose that

$$
d_{k}=d\left(x_{k}, x_{k+1}\right)>0
$$

for all $k \in \mathbb{N} \cup\{0\}$.

Next, we will show that

$$
d\left(x_{k+1}, x_{k+2}\right) \leq d\left(x_{k}, x_{k+1}\right)
$$


for all $k \in \mathbb{N} \cup\{0\}$. Assume to the contrary that

$$
d\left(x_{k+1}, x_{k+2}\right)>d\left(x_{k}, x_{k+1}\right)
$$

for some $k \in \mathbb{N} \cup\{0\}$. If $k$ is even, then $k=2 n$ for some $n \in \mathbb{N} \cup\{0\}$. Therefore, we have

$$
d\left(x_{2 n+1}, x_{2 n+2}\right)>d\left(x_{2 n}, x_{2 n+1}\right) .
$$

Since $x_{2 n} \in A, x_{2 n+1} \in B$ and $\alpha\left(x_{2 n}, x_{2 n+1}\right) \geq 1$, we have

$$
\psi\left(s^{3} d\left(x_{2 n+1}, x_{2 n+2}\right)\right)=\psi\left(s^{3} d\left(f x_{2 n}, g x_{2 n+1}\right)\right) \leq \delta \psi\left(M_{s}\left(x_{2 n}, x_{2 n+1}\right)\right),
$$

where

$$
\begin{aligned}
& M_{s}\left(x_{2 n}, x_{2 n+1}\right) \\
& =\max \left\{d\left(x_{2 n}, x_{2 n+1}\right), d\left(x_{2 n}, f x_{2 n}\right), d\left(x_{2 n+1}, g x_{2 n+1}\right), \frac{d\left(x_{2 n}, g x_{2 n+1}\right)+d\left(x_{2 n+1}, f x_{2 n}\right)}{2 s}\right\} \\
& =\max \left\{d\left(x_{2 n}, x_{2 n+1}\right), d\left(x_{2 n}, x_{2 n+1}\right), d\left(x_{2 n+1}, x_{2 n+2}\right), \frac{d\left(x_{2 n}, x_{2 n+2}\right)+d\left(x_{2 n+1}, x_{2 n+1}\right)}{2 s}\right\} \\
& =d\left(x_{2 n+1}, x_{2 n+2}\right) .
\end{aligned}
$$

Then we have

$$
\begin{aligned}
\psi\left(s^{3} d\left(x_{2 n+1}, x_{2 n+2}\right)\right) & \leq \delta \psi\left(d\left(x_{2 n+1}, x_{2 n+2}\right)\right) \leq \delta \psi\left(s^{3} d\left(x_{2 n+1}, x_{2 n+2}\right)\right) \\
& <\psi\left(s^{3} d\left(x_{2 n+1}, x_{2 n+2}\right)\right)
\end{aligned}
$$

which is a contradiction. Thus we have

$$
d\left(x_{2 n+1}, x_{2 n+2}\right) \leq d\left(x_{2 n}, x_{2 n+1}\right)=M_{s}\left(x_{2 n}, x_{2 n+1}\right)
$$

for all $n \in \mathbb{N} \cup\{0\}$. If $k$ is odd, then $k=2 n+1$ for some $n \in \mathbb{N} \cup\{0\}$. Therefore, we have

$$
d\left(x_{2 n+2}, x_{2 n+3}\right)>d\left(x_{2 n+1}, x_{2 n+2}\right) .
$$

Since $x_{2 n+2} \in A, x_{2 n+1} \in B$ and $\alpha\left(x_{2 n+1}, x_{2 n+2}\right) \geq 1$, we have

$$
\psi\left(s^{3} d\left(x_{2 n+3}, x_{2 n+2}\right)\right)=\psi\left(s^{3} d\left(f x_{2 n+2}, g x_{2 n+1}\right)\right) \leq \delta \psi\left(M_{s}\left(x_{2 n+2}, x_{2 n+1}\right)\right),
$$

where

$$
\begin{aligned}
M_{s}\left(x_{2 n+2}, x_{2 n+1}\right) & \\
= & \max \left\{d\left(x_{2 n+2}, x_{2 n+1}\right), d\left(x_{2 n+2}, f x_{2 n+2}\right), d\left(x_{2 n+1}, g x_{2 n+1}\right),\right. \\
& \left.\frac{d\left(x_{2 n+2}, g x_{2 n+1}\right)+d\left(x_{2 n+1}, f x_{2 n+2}\right)}{2 s}\right\}
\end{aligned}
$$




$$
\begin{aligned}
= & \max \left\{d\left(x_{2 n+2}, x_{2 n+1}\right), d\left(x_{2 n+2}, x_{2 n+3}\right), d\left(x_{2 n+1}, x_{2 n+2}\right),\right. \\
& \left.\frac{d\left(x_{2 n+2}, x_{2 n+2}\right)+d\left(x_{2 n+1}, x_{2 n+3}\right)}{2 s}\right\} \\
= & d\left(x_{2 n+2}, x_{2 n+3}\right) .
\end{aligned}
$$

Then we have

$$
\begin{aligned}
\psi\left(s^{3} d\left(x_{2 n+3}, x_{2 n+2}\right)\right) & \leq \delta \psi\left(d\left(x_{2 n+2}, x_{2 n+3}\right)\right) \\
& \leq \delta \psi\left(s^{3} d\left(x_{2 n+2}, x_{2 n+3}\right)\right) \\
& <\psi\left(s^{3} d\left(x_{2 n+2}, x_{2 n+3}\right)\right)
\end{aligned}
$$

which is a contradiction. Therefore, we have

$$
d\left(x_{2 n+2}, x_{2 n+3}\right) \leq d\left(x_{2 n+1}, x_{2 n+2}\right)=M_{s}\left(x_{2 n+1}, x_{2 n+2}\right)
$$

for all $n \in \mathbb{N} \cup\{0\}$. Hence the inequality (3.5) holds and then $\left\{d\left(x_{k}, x_{k+1}\right): k \in \mathbb{N} \cup\{0\}\right\}$ is bounded below and nonincreasing. Thus there exists $r \geq 0$ such that

$$
\lim _{k \rightarrow \infty} d\left(x_{k}, x_{k+1}\right)=r
$$

and we obtain

$$
\lim _{k \rightarrow \infty} M_{s}\left(x_{k}, x_{k+1}\right)=r
$$

Letting $n \rightarrow \infty$ in (3.2), using (3.8), (3.9), and the properties of $\psi$, we have

$$
\psi\left(s^{3} r\right) \leq \delta \psi(r) \leq \delta \psi\left(s^{3} r\right)
$$

Since $\delta<1$, we have $\psi\left(s^{3} r\right)=0$ and hence $r=0$. Thus we have

$$
\lim _{k \rightarrow \infty} d\left(x_{k}, x_{k+1}\right)=0
$$

Step II. We will show that $\left\{x_{n}\right\}$ is a $b$-Cauchy sequence in $X$. That is, for any $\epsilon>0$, there exists $k \in \mathbb{N}$ such that for all $m, n \geq k$, we get $d\left(x_{m}, x_{n}\right)<\epsilon$. Assume to the contrary that there exists $\epsilon>0$ for which we can find two subsequences $\left\{x_{m(k)}\right\}$ and $\left\{x_{n(k)}\right\}$ of $\left\{x_{n}\right\}$ such that $n(k)>m(k) \geq k$ and:

(a) $m(k)$ is even and $n(k)$ is odd;

(b)

$$
d\left(x_{m(k)}, x_{n(k)}\right) \geq \epsilon
$$

(c) $n(k)$ is the smallest number such that the condition (b) holds, i.e.,

$$
d\left(x_{m(k)}, x_{n(k)-1}\right)<\epsilon .
$$


From (3.11), (3.12), and the triangle inequality, we obtain

$$
\begin{aligned}
\epsilon & \leq d\left(x_{m(k)}, x_{n(k)}\right) \\
& \leq s\left[d\left(x_{m(k)}, x_{n(k)-1}\right)+d\left(x_{n(k)-1}, x_{n(k)}\right)\right] \\
& <s\left[\epsilon+d\left(x_{n(k)-1}, x_{n(k)}\right)\right] .
\end{aligned}
$$

Letting $k \rightarrow \infty$ in (3.13) and using (3.10), we have

$$
\epsilon \leq \limsup _{k \rightarrow \infty} d\left(x_{m(k)}, x_{n(k)}\right) \leq s \epsilon
$$

From the triangle inequality, we have

$$
d\left(x_{m(k)}, x_{n(k)}\right) \leq s\left[d\left(x_{m(k)}, x_{n(k)+1}\right)+d\left(x_{n(k)+1}, x_{n(k)}\right)\right]
$$

and

$$
d\left(x_{m(k)}, x_{n(k)+1}\right) \leq s\left[d\left(x_{m(k)}, x_{n(k)}\right)+d\left(x_{n(k)}, x_{n(k)+1}\right)\right] .
$$

Letting $k \rightarrow \infty$ in (3.15) and (3.16), it follows from (3.10) and (3.14) that

$$
\epsilon \leq s\left(\limsup _{k \rightarrow \infty} d\left(x_{m(k)}, x_{n(k)+1}\right)\right)
$$

and

$$
\limsup _{k \rightarrow \infty} d\left(x_{m(k)}, x_{n(k)+1}\right) \leq s^{2} \epsilon
$$

which implies that

$$
\frac{\epsilon}{s} \leq \limsup _{k \rightarrow \infty} d\left(x_{m(k)}, x_{n(k)+1}\right) \leq s^{2} \epsilon .
$$

Again, using the above process, we have

$$
\frac{\epsilon}{s} \leq \limsup _{k \rightarrow \infty} d\left(x_{n(k)}, x_{m(k)+1}\right) \leq s^{2} \epsilon
$$

Finally, we obtain

$$
d\left(x_{m(k)}, x_{n(k)+1}\right) \leq s\left[d\left(x_{m(k)}, x_{m(k)+1}\right)+d\left(x_{m(k)+1}, x_{n(k)+1}\right)\right] .
$$

Taking the limit supremum as $k \rightarrow \infty$ in (3.19), it follows from (3.10) and (3.17) that

$$
\frac{\epsilon}{s^{2}} \leq \limsup _{k \rightarrow \infty} d\left(x_{m(k)+1}, x_{n(k)+1}\right) \text {. }
$$

Similarly, we have

$$
\limsup _{k \rightarrow \infty} d\left(x_{m(k)+1}, x_{n(k)+1}\right) \leq s^{3} \epsilon
$$


Thus it follows from (3.20) and (3.21) that

$$
\frac{\epsilon}{s^{2}} \leq \limsup _{k \rightarrow \infty} d\left(x_{m(k)+1}, x_{n(k)+1}\right) \leq s^{3} \epsilon
$$

Since $\alpha$ is transitive, we have

$$
\alpha\left(x_{m(k)}, x_{n(k)}\right) \geq 1
$$

From (3.1), we have

$$
\psi\left(s^{3} d\left(x_{m(k)+1}, x_{n(k)+1}\right)\right)=\psi\left(s^{3} d\left(f x_{m(k)}, g x_{n(k)}\right)\right) \leq \delta \psi\left(M_{s}\left(x_{m(k)}, x_{n(k)}\right)\right),
$$

where

$$
\begin{aligned}
M_{s}\left(x_{m(k)}, x_{n(k)}\right) & \\
= & \max \left\{d\left(x_{m(k)}, x_{n(k)}\right), d\left(x_{m(k)}, f x_{m(k)}\right), d\left(x_{n(k)}, g x_{n(k)}\right),\right. \\
& \left.\frac{d\left(x_{m(k)}, g x_{n(k)}\right)+d\left(x_{n(k)}, f x_{m(k)}\right)}{2 s}\right\} \\
= & \max \left\{d\left(x_{m(k)}, x_{n(k)}\right), d\left(x_{m(k)}, x_{m(k)+1}\right), d\left(x_{n(k)}, x_{n(k)+1}\right),\right. \\
& \left.\frac{d\left(x_{m(k)}, x_{n(k)+1}\right)+d\left(x_{n(k)}, x_{m(k)+1}\right)}{2 s}\right\} .
\end{aligned}
$$

Letting the limit supremum as $k \rightarrow \infty$ in the above equation and using (3.11), (3.15), (3.17), (3.19), and (3.22), we have

$$
\epsilon=\max \left\{\epsilon, \frac{\frac{\epsilon}{s}+\frac{\epsilon}{s}}{2 s}\right\} \leq \limsup _{k \rightarrow \infty} M_{s}\left(x_{m(k)}, x_{n(k)}\right) \leq \max \left\{s \epsilon, \frac{s^{2} \epsilon+s^{2} \epsilon}{2 s}\right\}=s \epsilon .
$$

Letting $k \rightarrow \infty$ in (3.23), we have

$$
\begin{aligned}
\psi(s \epsilon) & =\psi\left(s^{3}\left(\frac{\epsilon}{s^{2}}\right)\right) \\
& \leq \psi\left(s^{3} \limsup _{k \rightarrow \infty} d\left(x_{m(k)+1}, x_{n(k)+1}\right)\right) \\
& \leq \delta \psi\left(\limsup _{k \rightarrow \infty} M_{s}\left(x_{m(k)}, x_{n(k)}\right)\right) \\
& \leq \delta \psi(s \epsilon) .
\end{aligned}
$$

Since $\delta<1$, we have $\psi(s \epsilon)=0$ and hence $\epsilon=0$, which is a contradiction. Therefore, $\left\{x_{n}\right\}$ is a $b$-Cauchy sequence in $X$.

Step III. We show that existence of a common fixed point of $f$ and $g$. Since $(X, d)$ is a complete $b$-metric space and $\left\{x_{n}\right\}$ is a $b$-Cauchy sequence in $X$, there exists $z \in X$ such that

$$
\lim _{n \rightarrow \infty} d\left(x_{n}, z\right)=0
$$


and so

$$
\lim _{n \rightarrow \infty} x_{n}=\lim _{n \rightarrow \infty} x_{2 n+1}=\lim _{n \rightarrow \infty} x_{2 n}=z .
$$

Since $\left\{x_{2 n}\right\}$ is a sequence in $A, A$ is closed, and $x_{2 n} \rightarrow z$, we have $z \in A$. Also, since $\left\{x_{2 n+1}\right\}$ is a sequence in $B, B$ is closed, and $x_{2 n+1} \rightarrow z$, we have $z \in B$.

Now, we show that $z$ is a fixed point of $f$ and $g$. Without loss of generality, we may assume that $f$ is continuous. Since $\left\{x_{2 n}\right\} \rightarrow z$, we get $x_{2 n+1}=f x_{2 n} \rightarrow f z$. By the uniqueness of the limit, we have $z=f z$.

Now, we show that $z=g z$. Since $z \in A, z \in B$, and $\alpha(z, z) \geq 1$, we have

$$
\begin{aligned}
\psi\left(s^{3} d(z, g z)\right) & =\psi\left(s^{3} d(f z, g z)\right) \\
& \leq \delta \psi\left(M_{s}(z, z)\right) \\
& =\delta \psi\left(\max \left\{d(z, z), d(z, f z), d(z, g z), \frac{d(z, g z)+d(z, f z)}{2 s}\right\}\right) \\
& =\delta \psi(d(z, g z)) \\
& \leq \delta \psi\left(s^{3} d(z, g z)\right) .
\end{aligned}
$$

Since $\delta<1$, it follows that $d(z, g z)=0$ and hence $z=g z$. Therefore, $z$ is a common fixed point of $f$ and $g$. This completes the proof.

Theorem 3.3 can be proved without assuming the $b$-continuity of $f$ or the $b$-continuity of $g$. For this instance, we assume that $X$ satisfies the following property.

Definition 3.4 Let $(X, d)$ be a $b$-metric space and $\alpha: X \times X \rightarrow[0, \infty)$ be a mapping. A space $X$ satisfies the property (Q) if $\left\{x_{n}\right\}$ is a sequence in $X$ such that $\alpha\left(x_{n}, x_{n+1}\right) \geq 1$ for all $n \in \mathbb{N}$ and $x_{n} \rightarrow x$ as $n \rightarrow \infty$, then $\alpha\left(x_{n}, x\right) \geq 1$ for all $n \in \mathbb{N}$.

Now, we state and prove the following result.

Theorem 3.5 Let $(X, d)$ be a complete $b$-metric space with coefficient $s \geq 1$ and $A, B$ be nonempty closed subsets of $X$. Suppose that $\alpha: X \times X \rightarrow[0, \infty), \psi:[0, \infty) \rightarrow[0, \infty)$ and $f, g: X \rightarrow X$ are four mappings such that the pair $(f, g)$ is $\alpha-(A, B)$-weakly increasing and the following conditions hold:

(1) the pair $(f, g)$ is a cyclic $\alpha-(\psi, A, B)_{s}$-contraction;

(2) $X$ satisfies the property $(\mathrm{Q})$;

(3) $\alpha$ is a transitive mapping;

(4) if $\left\{x_{n}\right\}$ is a sequence in $X$ such that $\alpha\left(x_{n}, x_{n+1}\right) \geq 1$ for all $n \in \mathbb{N}$ and $x_{n} \rightarrow z$ as

$n \rightarrow \infty$, then $\alpha(z, z) \geq 1$.

Then $f$ and $g$ have a common fixed point in $A \cap B$.

Proof Now, we prove the reasoning of Theorem 3.3 step by step to construct a sequence $\left\{x_{n}\right\}$ in $X$ with

$$
\alpha\left(x_{n}, x_{n+1}\right) \geq 1, \quad x_{2 n} \in A, \quad x_{2 n+1} \in B
$$


for all $n \in \mathbb{N}$ and $x_{n} \rightarrow u$ for some $u \in X$. Since $x_{2 n} \rightarrow u, x_{2 n+1} \rightarrow u, A$ and $B$ are closed subsets of $X$, we have $u \in A \cap B$. Using the property (Q), we have $\alpha\left(x_{n}, u\right) \geq 1$ for all $n \in \mathbb{N}$. Since $x_{2 n} \in A, u \in B$, and $\alpha\left(x_{2 n}, u\right) \geq 1$ for all $n \in \mathbb{N}$, we have

$$
\begin{aligned}
\psi & \left(s^{3} d\left(x_{2 n+1}, g u\right)\right) \\
& =\psi\left(s^{3} d\left(f x_{2 n}, g u\right)\right) \leq \delta \psi\left(M_{s}\left(x_{2 n}, u\right)\right) \\
& =\delta \psi\left(\max \left\{d\left(x_{2 n}, u\right), d\left(x_{2 n}, f x_{2 n}\right), d(u, g u), \frac{d\left(x_{2 n}, g u\right)+d\left(u, f x_{2 n}\right)}{2 s}\right\}\right) \\
& =\delta \psi\left(\max \left\{d\left(x_{2 n}, u\right), d\left(x_{2 n}, x_{2 n+1}\right), d(u, g u), \frac{d\left(x_{2 n}, g u\right)+d\left(x_{2 n+1}, u\right)}{2 s}\right\}\right)
\end{aligned}
$$

for all $n \in \mathbb{N}$. Taking the limit supremum as $n \rightarrow \infty$ in the above inequality, we have

$$
\begin{aligned}
\psi\left(s^{2} d(u, g u)\right) & =\psi\left(s^{3}\left(\frac{1}{s} d(u, g u)\right)\right) \\
& \leq \psi\left(s^{3} \limsup _{n \rightarrow \infty} d\left(x_{2 n+1}, g u\right)\right) \\
& \leq \delta \psi\left(\max \left\{0,0, d(u, g u), \frac{d(u, g u)}{2}\right\}\right) \\
& =\delta \psi(d(u, g u)) \\
& \leq \delta \psi\left(s^{2} d(u, g u)\right) .
\end{aligned}
$$

Since $\delta<1$ and $s \geq 1$, we have $d(u, g u)=0$ and hence $g u=u$. Similarly, we may show that $f u=u$. Thus $u$ is a common fixed point of $f$ and $g$. This completes the proof.

Taking $f=g$ in Theorems 3.3 and 3.5, we have the following result.

Corollary 3.6 Let $(X, d)$ be a complete $b$-metric space with coefficient $s \geq 1$ and $A, B$ be nonempty closed subsets of $X$. Suppose that $\alpha: X \times X \rightarrow[0, \infty), \psi:[0, \infty) \rightarrow[0, \infty)$ and $f:$ $X \rightarrow X$ are three mappings such that $\alpha(f x, f x) \geq 1$ for all $x \in X$ and the following conditions hold:

(1) $\psi$ is altering distance, $f$ is a cyclic mapping, and there exists $0<\delta<1$ such that

$$
\begin{aligned}
& x \in A, y \in B \quad \text { with } \alpha(x, y) \geq 1 \text { or } \alpha(y, x) \geq 1 \\
& \Rightarrow \psi\left(s^{3} d(f x, f y)\right) \leq \delta \psi\left(\max \left\{d(x, y), d(x, f x), d(y, f y), \frac{d(x, f y)+d(y, f x)}{2 s}\right\}\right)
\end{aligned}
$$

(2) $f$ is b-continuous;

(3) $\alpha$ is a transitive mapping;

(4) if $\left\{x_{n}\right\}$ is a sequence in $X$ such that $\alpha\left(x_{n}, x_{n+1}\right) \geq 1$ for all $n \in \mathbb{N}$ and $x_{n} \rightarrow z$ as

$n \rightarrow \infty$, then $\alpha(z, z) \geq 1$.

Then $f$ has a fixed point in $A \cap B$.

Corollary 3.7 Let $(X, d)$ be a complete b-metric space with coefficient $s \geq 1$ and $A, B$ be nonempty closed subsets of $X$. Suppose that $\alpha: X \times X \rightarrow[0, \infty), \psi:[0, \infty) \rightarrow[0, \infty)$, and $f:$ 
$X \rightarrow X$ are three mappings such that $\alpha(f x, f x) \geq 1$ for all $x \in X$ and the following conditions hold:

(1) $\psi$ is altering distance, $f$ is a cyclic mapping, and there exists $0<\delta<1$ such that

$$
\begin{aligned}
x \in A, y \in B \quad \text { with } \alpha(x, y) \geq 1 \text { or } \alpha(y, x) \geq 1 \\
\Rightarrow \quad \psi\left(s^{3} d(f x, f y)\right) \leq \delta \psi\left(\max \left\{d(x, y), d(x, f x), d(y, f y), \frac{d(x, f y)+d(y, f x)}{2 s}\right\}\right) ;
\end{aligned}
$$

(2) $X$ satisfies the property (Q);

(3) $\alpha$ is a transitive mapping;

(4) if $\left\{x_{n}\right\}$ is a sequence in $X$ such that $\alpha\left(x_{n}, x_{n+1}\right) \geq 1$ for all $n \in \mathbb{N}$ and $x_{n} \rightarrow z$ as $n \rightarrow \infty$ then $\alpha(z, z) \geq 1$.

Then $f$ has a fixed point in $A \cap B$.

Now, we give an example to illustrate the utility of Theorem 3.5.

Example 3.8 Let $X=\mathbb{N} \cup\{\infty\}$ and $d: X \times X \rightarrow[0, \infty)$ be defined by

$$
d(m, n)= \begin{cases}0, & \text { if } m=n ; \\ \left|\frac{1}{m}-\frac{1}{n}\right|, & \text { if one of } m, n \text { is even and the other is even or } \infty ; \\ 5, & \text { if one of } m, n \text { is odd and the other is odd (and } m \neq n) \text { or } \infty \\ 2, & \text { otherwise. }\end{cases}
$$

Thus $(X, d)$ is a complete $b$-metric space with coefficient $s=\frac{5}{2}$. Let

$$
A=X-\{32 n: n \in \mathbb{N}\}
$$

and

$$
B=\{16 n: n \in \mathbb{N}\} \cup\{\infty\} .
$$

Note that $A$ and $B$ are nonempty closed subset of $X$ and $X=A \cup B$. Define three mappings $f, g: X \rightarrow X$ and $\alpha: X \times X \rightarrow[0, \infty)$ by

$$
\begin{aligned}
& f n= \begin{cases}16 n, & \text { if } n \in \mathbb{N} ; \\
\infty, & \text { if } n=\infty,\end{cases} \\
& g n= \begin{cases}n, & \text { if } n \notin B ; \\
\infty, & \text { if } n \in B,\end{cases}
\end{aligned}
$$

and

$$
\alpha(m, n)= \begin{cases}1, & m \leq n \\ 0, & m>n\end{cases}
$$

Also, define $\psi:[0, \infty) \rightarrow[0, \infty)$ by $\psi(t)=\sqrt{t}$ for all $t \in[0, \infty)$.

Now, we show that all the conditions in Theorem 3.5 hold in this situation. 
To prove that $(f, g)$ is $\alpha-(A, B)$-weakly increasing. Let $n \in A$. Then it follows that $f n \in B$ and so $g f n=\infty$. Thus $\alpha(f n, g f n) \geq 1$ for all $n \in A$. Let $n \in B$. Then $g n=\infty$ and $f g n=\infty$. Thus $\alpha(g n, f g n) \geq 1$ for all $n \in B$. Therefore, $(f, g)$ is $\alpha$ - $(A, B)$-weakly increasing.

Next, we show that $(f, g)$ is a cyclic $\alpha-(\psi, A, B)_{s}$-contraction.

(a) It is easy to see that $\psi$ is an altering distance function;

(b) since $f(A) \subseteq\{16 n: n \in \mathbb{N}\} \cup\{\infty\}=B$ and $g(B)=\{\infty\} \subseteq A$, we conclude that $A \cup B$ has a cyclic representation with respect to the pair $(f, g)$;

(c) here, we show that $f$ and $g$ satisfy the condition (3.1). Let $m \in A$ and $n \in B$. We show this proof in two cases.

Case I: Assume that $m \in A /\{\infty\}$. Then we have

$$
\begin{aligned}
\psi\left(s^{3} d(f m, g n)\right) & =\psi\left(\left(\frac{5}{2}\right)^{3} d(16 m, \infty)\right) \\
& =\sqrt{\frac{5^{3}}{2^{3} \cdot 16} \cdot\left|\frac{1}{m}\right|} \\
& =\frac{5 \sqrt{5}}{8 \sqrt{2}} \cdot \psi(d(m, n)) \\
& \leq \delta \psi\left(M_{s}(m, n)\right) .
\end{aligned}
$$

Case II: Assume that $m=\infty$. Now, we have $d(f m, g n)=0$. Then we have nothing to prove. From (a), (b), and (c), it follows that $(f, g)$ is a cyclic $\alpha-(\psi, A, B)_{s}$-contraction with $\delta=$ $\frac{5 \sqrt{5}}{8 \sqrt{2}}<1$. It is easily to show that $X$ satisfies the property $(\mathrm{Q})$ and $\alpha$ is transitive. Moreover, the condition (4) of Theorem 3.5 holds. Thus $f$ and $g$ satisfy all the conditions of Theorem 3.5. Hence $f$ and $g$ have a common fixed point, i.e., a point $\infty$ is a common fixed point of $f$ and $g$.

\section{Some particular cases}

In this section, we give some fixed point results on partially ordered $b$-metric spaces which can be regarded as consequences of the results presented in the previous section.

Now, we need the following notions and definitions for the main results in this section.

Definition 4.1 Let $X$ be a nonempty set. Then $(X, d, \preceq)$ is called a partially ordered $b$ metric space if $(X, d)$ is a $b$-metric space and $(X, \preceq)$ is a partially ordered set.

Definition 4.2 Let $A, B$ be two nonempty closed subsets of a complete partially ordered $b$-metric space $(X, d, \preceq)$ with coefficient $s \geq 1$ and $\psi:[0, \infty) \rightarrow[0, \infty), f, g: X \rightarrow X$ be three mappings. The pair $(f, g)$ is called a cyclic $(\psi, A, B)_{s}$-contraction if

(1) $\psi$ is an altering distance function;

(2) $A \cup B$ has a cyclic representation w.r.t. the pair $(f, g)$;

(3) there exists $0<\delta<1$ such that the following condition holds:

$$
x \in A, y \in B \quad \text { with } x \preceq y \text { or } y \preceq x \quad \Longrightarrow \quad \psi\left(s^{3} d(f x, g y)\right) \leq \delta \psi\left(M_{s}(x, y)\right) .
$$

Definition 4.3 Let $(X, d, \preceq)$ be a complete partially ordered $b$-metric space with coefficient $s \geq 1$ and $A, B$ be nonempty closed subsets of $X$ with $X=A \cup B$. Let $f, g: X \rightarrow X$ be 
two mappings. The pair $(f, g)$ is said to be $(A, B)$-weakly increasing if $f x \preceq g f x$ for all $x \in A$ and $g x \preceq f g x$ for all $x \in B$.

Definition 4.4 We say that a partially ordered $b$-metric space $(X, d, \preceq)$ satisfies the prop$\operatorname{erty}(\mathrm{P})$ if $\left\{x_{n}\right\}$ being $\mathrm{a} \preceq$-nondecreasing sequence in $X$ and $x_{n} \rightarrow x$ as $n \rightarrow \infty$, then $x_{n} \preceq x$ for all $n \in \mathbb{N}$.

Theorem 4.5 Let $(X, d, \preceq)$ be a complete partially ordered b-metric space with coefficient $s \geq 1$ and $A, B$ be nonempty closed subsets of $X$. Suppose that $f, g: X \rightarrow X$ are two mappings such that the pair $(f, g)$ is $(A, B)$-weakly increasing and the following conditions hold:

(1) the pair $(f, g)$ is a cyclic $(\psi, A, B)_{s}$-contraction;

(2) $f$ or $g$ is b-continuous.

Then $f$ and $g$ have a common fixed point in $A \cap B$.

Proof Define a mapping $\alpha: X \times X \rightarrow[0, \infty)$ by

$$
\alpha(x, y)= \begin{cases}1, & x \preceq y \\ 0, & \text { otherwise }\end{cases}
$$

in Theorem 3.3, then we get this result.

By using the same technique in Theorem 4.5 with Theorem 3.5 and Corollaries 3.6 and 3.7, we get the following result.

Theorem 4.6 Let $(X, d, \preceq)$ be a complete partially ordered $b$-metric space with coefficient $s \geq 1$ and $A, B$ be nonempty closed subsets of $X$. Suppose that $f, g: X \rightarrow X$ are two mappings such that the pair $(f, g)$ is $(A, B)$-weakly increasing and the following condition holds:

(1) the pair $(f, g)$ is a cyclic $(\psi, A, B)_{s}$-contraction;

(2) $X$ satisfies the property $(\mathrm{P})$.

Then $f$ and $g$ have a common fixed point in $A \cap B$.

Corollary 4.7 Let $(X, d, \preceq)$ be a complete partially ordered b-metric space with coefficient $s \geq 1$ and $A, B$ be nonempty closed subsets of $X$ with $X=A \cup B$. Suppose that $\psi:[0, \infty) \rightarrow$ $[0, \infty)$ and $f: X \rightarrow X$ are two mappings such that $f x \preceq f f x$ for all $x \in X$ and the following conditions hold:

(1) $\psi$ is an altering distance, $f$ is a cyclic mapping and there exists $0<\delta<1$ such that

$$
\begin{aligned}
x \in A, y \in B \quad \text { with } x \preceq y \text { or } y \preceq x \\
\Rightarrow \quad \psi\left(s^{3} d(f x, f y)\right) \leq \delta \psi\left(\max \left\{d(x, y), d(x, f x), d(y, f y), \frac{d(x, f y)+d(y, f x)}{2 s}\right\}\right) ;
\end{aligned}
$$

(2) $f$ is b-continuous.

Then $f$ has a fixed point in $A \cap B$.

Corollary 4.8 Let $(X, d, \preceq)$ be a complete partially ordered b-metric spaces with coefficient $s \geq 1$ and $A, B$ be nonempty closed subsets of $X$ with $X=A \cup B$. Suppose that $\psi:[0, \infty) \rightarrow$ $[0, \infty)$ and $f: X \rightarrow X$ are two mappings such that $f x \preceq f f x$ for all $x \in X$ and the following conditions hold: 
(1) $\psi$ is altering distance, $f$ is a cyclic mapping, and there exists $0<\delta<1$ such that

$$
\begin{aligned}
x \in A, y \in B \quad \text { with } x \preceq y \text { or } y \preceq x \\
\\
\Longrightarrow \quad \psi\left(s^{3} d(f x, f y)\right) \leq \delta \psi\left(\max \left\{d(x, y), d(x, f x), d(y, f y), \frac{d(x, f y)+d(y, f x)}{2 s}\right\}\right) ;
\end{aligned}
$$

(2) $X$ satisfies the property (P).

Then $f$ has a fixed point in $A \cap B$.

In 2013, Shatanawi and Postolache [6] introduced the notion of a cyclic $(\psi, A, B)$ contraction pair in partially ordered metric spaces as follows.

Definition $4.9([6])$ Let $(X, d, \preceq)$ be a partially ordered metric space and $A, B$ be two nonempty closed subsets of $X$. Let $\psi:[0, \infty) \rightarrow[0, \infty)$ and $f, g: X \rightarrow X$ be three mappings. The pair $(f, g)$ is called a cyclic $(\psi, A, B)$-contraction if

(1) $\psi$ is an altering distance function;

(2) $A \cup B$ has a cyclic representation with respect to the pair $(f, g)$;

(3) there exists $0<\delta<1$ such that, for any comparable elements $x, y \in X$ with $x \in A$ and $y \in B$

$$
\psi(d(f x, g y)) \leq \delta \psi\left(\max \left\{d(x, y), d(x, f x), d(y, g y), \frac{d(x, g y)+d(y, f x)}{2}\right\}\right)
$$

Since the class of $b$-metric spaces is effectively larger than that of metric spaces, we can obtain the result of Shatanawi and Postolache [6] from our results.

Corollary $4.10([6])$ Let $(X, d, \preceq)$ be a complete partially ordered metric spaces and $A, B$ be nonempty closed subsets of $X$. Suppose that $f, g: X \rightarrow X$ are two mappings such that the pair $(f, g)$ is $(A, B)$-weakly increasing and the following conditions hold:

(1) the pair $(f, g)$ is a cyclic $(\psi, A, B)$-contraction;

(2) $f$ or $g$ is continuous.

Then $f$ and $g$ have a common fixed point in $A \cap B$.

Corollary $4.11([6])$ Let $(X, d, \preceq)$ be a complete partially ordered metric space and $A, B$ be nonempty closed subsets of $X$. Suppose that $f, g: X \rightarrow X$ are two mappings such that the pair $(f, g)$ is $(A, B)$-weakly increasing and the following conditions hold:

(1) the pair $(f, g)$ is a cyclic $(\psi, A, B)$-contraction;

(2) $X$ satisfies the property (P).

Then $f$ and $g$ have a common fixed point in $A \cap B$.

Corollary $4.12([6])$ Let $(X, d, \preceq)$ be a complete partially ordered metric space and $A, B$ be nonempty closed subsets of $X$ with $X=A \cup B$. Suppose that $\psi:[0, \infty) \rightarrow[0, \infty)$ and $f: X \rightarrow X$ are two mappings such that $f x \preceq f f x$ for all $x \in X$ and the following conditions hold:

(1) $\psi$ is altering distance, $f$ is a cyclic mapping, and there exists $0<\delta<1$ such that

$$
\begin{aligned}
x \in A, y \in B \quad \text { with } x \preceq y \text { or } y \preceq x \\
\Longrightarrow \quad \psi(d(f x, f y)) \leq \delta \psi\left(\max \left\{d(x, y), d(x, f x), d(y, f y), \frac{d(x, f y)+d(y, f x)}{2}\right\}\right) ;
\end{aligned}
$$


(2) $f$ is continuous.

Then $f$ has a fixed point in $A \cap B$.

Corollary $4.13([6])$ Let $(X, d, \preceq)$ be a complete partially ordered metric spaces and $A, B$ be nonempty closed subsets of $X$ with $X=A \cup B$. Suppose that $\psi:[0, \infty) \rightarrow[0, \infty)$ and $f: X \rightarrow X$ are two mappings such that $f x \preceq f f x$ for all $x \in X$ and the following conditions hold:

(1) $\psi$ is altering distance, $f$ is a cyclic mapping and there exists $0<\delta<1$ such that

$$
\begin{aligned}
x \in A, y \in B \quad \text { with } x \preceq y \text { or } y \preceq x \\
\Longrightarrow \quad \psi(d(f x, f y)) \leq \delta \psi\left(\max \left\{d(x, y), d(x, f x), d(y, f y), \frac{d(x, f y)+d(y, f x)}{2}\right\}\right) ;
\end{aligned}
$$

(2) $X$ satisfies the property (P).

Then $f$ has a fixed point in $A \cap B$.

\section{Conclusions}

The study of fixed points of mappings and common fixed points of pair of mappings satisfying cyclic contractive conditions has been the focus of vigorous research activity in the last years. As a consequence, many mathematicians obtained more results in this direction. In this paper, the concept of new generalized cyclic contraction pairs in $b$-metric spaces is introduced. Based on this concept, we have studied the existence of common fixed point results for such pairs in $b$-metric spaces. Some illustrative examples are furnished which demonstrate the validity of the hypotheses and degree of utility of our results. Also, we can derive some common fixed points existence results for mappings satisfying a generalized cyclic contractive condition in partially ordered $b$-metric spaces from our main results. These results improve and generalize the main results of Shatanawi and Postolache [6].

\section{Competing interests}

The authors declare that they have no competing interests.

Authors' contributions

All authors contributed equally to the writing of this paper. All authors read and approved the final manuscript.

\section{Author details}

'Department of Mathematics and Statistics, Faculty of Science and Technology, Thammasat University Rangsit Center, Pathumthani, 12121, Thailand. '2Department of Mathematics Education and the RINS, Gyeongsang National University, Jinju, 660-701, Korea. ${ }^{3}$ Department of Mathematics, King Abdulaziz University, Jeddah, 21589, Saudi Arabia.

\section{Acknowledgements}

This work was support by Research Professional Development Project under the Science Achievement Scholarship of Thailand (SAST). The second author would like to thank the Thailand Research Fund and Thammasat University under Grant No. TRG5780013 for financial support during the preparation of this manuscript. The third author was supported by the Basic Science Research Program through the National Research Foundation of Korea (NRF) funded by the Ministry of Science, ICT and future Planning (2014R1A2A2A01002100).

Received: 21 April 2015 Accepted: 21 August 2015 Published online: 17 September 2015

\section{References}

1. Kirk, WA, Srinivasan, PS, Veeramani, P: Fixed points for mappings satisfying cyclical contractive conditions. Fixed Point Theory 4, 79-89 (2003)

2. Aydi, H, Vetro, C, Sintunavarat, W, Kumam, P: Coincidence and fixed points for contractions and cyclical contractions in partial metric spaces. Fixed Point Theory Appl. 2012, 124 (2012) 
3. Nashine, HK, Sintunavarat, W, Kumam, P: Cyclic generalized contractions and fixed point results with applications to an integral equation. Fixed Point Theory Appl. 2012, 217 (2012)

4. Sintunavarat, W, Kumam, P: Common fixed point theorem for cyclic generalized multi-valued contraction mappings. Appl. Math. Lett. 25, 1849-1855 (2012)

5. Yamaod, $\mathrm{O}$, Sintunavarat, $\mathrm{W}$ : Some fixed point results for generalized contraction mappings with cyclic $(\alpha, \beta)$-admissible mapping in multiplicative metric spaces. J. Inequal. Appl. 2014, 488 (2014)

6. Shatanawi, W, Postolache, M: Common fixed point results for mappings under nonlinear contraction of cyclic form in ordered metric spaces. Fixed Point Theory Appl. 2013, 60 (2013)

7. Khan, MS, Swaleh, M, Sessa, S: Fixed point theorems by altering distances between the points. Bull. Aust. Math. Soc. 30, 1-9 (1984)

8. Bakhtin, IA: The contraction mapping principle in almost metric spaces. In: Functional Analysis, vol. 30, pp. 26-37. UI'yanovsk. Gos. Ped. Inst., UI'yanovsk (1989)

9. Ansari, HK, Chandok, S, lonescu, C: Fixed point theorems on b-metric spaces for weak contractions with auxiliary functions. J. Inequal. Appl. 2014, 429 (2014)

10. Boriceanu, M, Bota, M, Petrusel, A: Multivalued fractals in b-metric spaces. Cent. Eur. J. Math. 8(2), 367-377 (2010)

11. Bota, M, Molnar, A, Csaba, V: On Ekeland's variational principle in b-metric spaces. Fixed Point Theory 12, 21-28 (2011)

12. Czerwik, S: Nonlinear set-valued contraction mappings in b-metric spaces. Atti Semin. Mat. Fis. Univ. Modena 46, 263-276 (1998)

13. Shatanawi, W, Pitea, A, Lazovic, R: Contraction conditions using comparison functions on $b$-metric spaces. Fixed Point Theory Appl. 2014, 135 (2014)

14. Aghajani, A, Abbas, M, Roshan, JR: Common fixed point of generalized weak contractive mappings in partially ordered b-metric spaces. Math. Slovaca 64(4), 941-960 (2014)

15. Sintunavarat, $\mathrm{W}$ : Generalized Ulam-Hyers stability, well-posedness and limit shadowing of fixed point problems for $\alpha$ - $\beta$-contraction mapping in metric spaces. Sci. World J. 2014, 569174 (2014)

16. Latif, A, Mongkolkeha, C, Sintunavarat, W: Fixed point theorems for generalized $\alpha$ - $\beta$-weakly contraction mappings in metric spaces and applications. Sci. World J. 2014, 784207 (2014)

\section{Submit your manuscript to a SpringerOpen ${ }^{\ominus}$ journal and benefit from:}

- Convenient online submission

- Rigorous peer review

- Immediate publication on acceptance

- Open access: articles freely available online

- High visibility within the field

- Retaining the copyright to your article 